\title{
Contrasted photochromic and luminescent properties in dinuclear Pt(II) complexes linked through a central dithienylethene unit
}

Received 00th January 20xx, Accepted 00th January 20xx

DOI: $10.1039 / \times 0 \times x 00000 x$

\author{
Julien Boixel*a, Yifan Zhu ${ }^{\mathrm{b}}$, Hubert Le Bozec ${ }^{\mathrm{a}}$, Mohamed Ali Benmensour ${ }^{\mathrm{a}}$, Abdou Boucekkine ${ }^{\mathrm{a}}$ \\ Keith Man-Chung Wong ${ }^{b}$, Alessia Colombo ${ }^{c}$, Dominique Roberto ${ }^{c}$, Véronique Guerchais*a and \\ Denis Jacquemin*d,e
}

www.rsc.org/

We disclose two unprecedented complexes built with a central dithienylethene photochrome connecting two cyclometalated $\operatorname{Pt}$ (II) moieties either on the reactive carbon atoms or on the lateral non-reactive carbon atoms of the photochrome. The two systems show vastly different properties that are rationalised thanks to quantum-chemical calculations.

The combination of transition metals with ligands containing photochromic DiThienylEthene (DTE) units has opened new perspectives in the design of photoswitchable molecules. These systems have notably been exploited for the photomodulation of their electronic, photophysical and nonlinear optical (NLO) properties. ${ }^{1}$ Besides synthetic aspects, there is one key advantage of using a metallic center to build a multi-DTE molecule: all DTE units generally remain photochromic in metal-containing DTE, while, in contrast, the photoswitching is often limited to a single DTE only in pure organic multi-DTE. ${ }^{2}$ Our interest in photochromic properties of both organic and organometallic photochromes has led to extensive theoretical studies in order to unravel the key parameters governing the photo-reactivity in multi-DTE systems. ${ }^{3}$ It was shown that several parameters, i.e., the stability of the formed product, the geometry of the intermediates and the nature of the excitedstates, have to be controlled to reach fully-active multi-DTE compounds. ${ }^{3}$ In this context, we have recently reported the synthesis of monometallic metal complexes containing from 2 to 6 DTEs at their peripheral position, for the on/off modulation of both their second-order NLO responses ${ }^{4}$ and luminescence

\footnotetext{
a. Institut des Sciences Chimiques de Rennes, UMR-6626 CNRS-Université de Rennes 1, Campus Beaulieu, 35042 Rennes Cedex, France.

Email : julien.boixel@univ-rennes1.fr, veronique.guerchais@univ-rennes1.fr

b. Department of Chemistry, South University of Science \& Technology of China, No. 1088, Tangchang Boulevard, Nanshan District, Shenzhen, Guangdong, P. R. China

c. Dipartimento di Chimica, Università degli Studi di Milano and UdR INSTM di Milano, via Golgi 19, Milano, 20133, Italy.

d. Laboratoire CEISAM, UMR CNRS 6230, Université de Nantes, 2 rue de la houssinière, 44322 Nantes Cedex 03, France.Denis.Jacquemin@univ-nantes.fr

e. Institut Universitaire de France, 1 rue Descartes, F-75005 Paris Cedex 05, France.

+ Electronic Supplementary Information (ESI) available: Methods, synthesis and characterisations, variable-temperature NMR analysis, XRD data, photophysical studies for Pt-B including excitation spectrm, NMR experiment for photocyclisation of Pt-A, additional theoretical data. See DOI: 10.1039/x0xx00000x
}

properties. ${ }^{4 e}$ Binuclear metal complexes containing a DTE ligand bridging two metal centers also represent an interesting class of photochromic molecular switches. Indeed, monophotochromic bimetallic species featuring a classical design with the metal moieties located on each sides of the DTE and separated by a $\pi$-conjugated fragment, often show valuable photoswitching performances. ${ }^{5}$

As the extension of our previous works on mononuclear photochromic platinum complexes, ${ }^{6}$ we report the synthesis and characterisation of two new DTE-based di-platinum complexes, Pt-A and Pt-B, where the two metal moieties are differently framing the same DTE core (Scheme 1). Pt-A displays a classical design whereas, in the non-classical Pt-B, the cyclometalated $\mathrm{Pt}(\mathrm{II})$ acetylide moieties are directly linked to the reactive carbon atoms. The investigation of these systems provides a unique opportunity to obtain insights into the working mechanisms of these complex architectures. In particular, the possible conformations of the DTE core, parallel (P) and anti-parallel (AP) conformers in the open form in addition to the closed form, offer several interaction modes for the two Pt moieties making it possible to tune the competition between photochemistry (DTE closing) and luminescence (Pt).

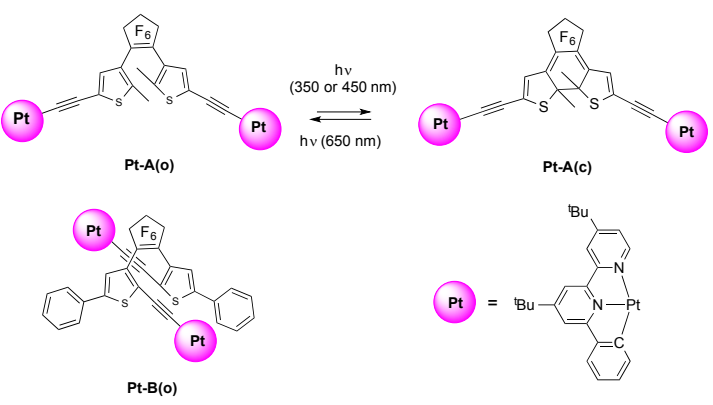

Scheme 1 Top: Classical DTE-based $\left(\mathrm{N}^{\wedge} \mathrm{N}^{\wedge} \mathrm{C}\right) \mathrm{Pt}(\mathrm{II})$ complex Pt-A in its open (left) and closed (right) forms. Bottom left: non classical DTE-based $\left(\mathrm{N}^{\wedge} \mathrm{N}^{\wedge} \mathrm{C}\right) \mathrm{Pt}(\mathrm{II})$ complex (open) Pt-B. 
Pt-A and Pt-B were prepared, following a reported procedure, ${ }^{7}$ upon treatment of $\left(\mathrm{N}^{\wedge} \mathrm{N}^{\wedge} \mathrm{C}\right) \mathrm{Pt}-\mathrm{Cl}\left(\mathrm{N}^{\wedge} \mathrm{N}^{\wedge} \mathrm{C}: 4,4\right.$-di(tert-butyl)6-phenyl-2,2'-bipyridine) with the appropriate DTE-based alkynes (see the ESI $\dagger$ ). In both cases, the ${ }^{1} \mathrm{H}$ NMR spectrum $\left(\mathrm{CD}_{2} \mathrm{Cl}_{2}\right)$ shows one set of signals, as the result of either a fast equilibrium between the AP/P forms, or the presence of one species only. Variable-temperature NMR experiments did not allow determining the ratio of the AP/P forms nor the nature of the unique conformer (AP/P) if any (see the ESI $\dagger$ ).

Subsequent diffusion of diethyl ether vapour into a dichloromethane solution of Pt-B gave red crystals suitable for crystallographic analysis. Figure 1 depicts the structure of Pt-B showing that the DTE unit adopts an AP conformation, the terminal phenyl ring being placed almost parallel to the $\mathrm{N}^{\wedge} \mathrm{N}^{\wedge} \mathrm{C}$ ligand (interplanar angle $9.37^{\circ}$ ) with a distance between the centroids of the terminal phenyl and the central pyridine ring of ca. $4 \AA$, hinting for (weak) $\pi$-stacking interactions. The same structure was found to be the most stable in solutions by DFT calculations of Pt-B, though the corresponding $\mathrm{P}$ conformer presents a very close energy according to theory (see the ESI $\dagger$ ). We reasoned that the energy barrier between the two forms is likely to be high in the present case as the metal moieties are directly linked to the reactive carbons, hinting that large motions would be necessary to go from the AP to the $\mathrm{P}$ conformers (and vice-versa). These experimental and theoretical data suggest that Pt-B exits as the sole AP conformer.

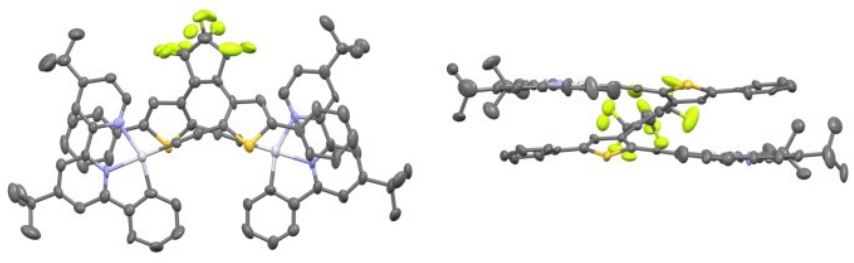

Figure 1 Representation of Pt-B (side and bottom views). Hydrogen atoms have been omitted for clarity. Thermal ellipsoids are shown at the $50 \%$ probability level.

The absorption spectra of Pt-A and Pt-B are shown in Figure 2 whereas the photophysical data are listed in Table 1. The absorption spectra of the complexes in their open DTE forms have very similar profiles. Consistently with previous works, ${ }^{6,7}$ the high-energy absorption bands at ca. 300-400 nm, with $\varepsilon$ of ca. $25 \times 10^{3} \mathrm{M}^{-1} \mathrm{~cm}^{-1}$, were assigned to intraligand (IL) transitions, some presenting a charge-transfer (CT) character from the DTE core to the phenylbipyridine, whereas the visible bands at 400-550 nm, with $\varepsilon$ of ca. $5 \times 10^{3} \mathrm{M}^{-1} \mathrm{~cm}^{-1}$, include metal-to-ligand charge-transfer (MLCT, $d(\mathrm{Pt}) \rightarrow \pi^{*}\left(\mathrm{~N}^{\wedge} \mathrm{N}^{\wedge} \mathrm{C}\right)$ ) transitions mixed with ligand-to-ligand $\mathrm{CT}$ (LLCT, $\pi(\mathrm{C} \equiv \mathrm{C} /$ thiophene $\left.) \rightarrow \pi^{*}\left(\mathrm{~N}^{\wedge} \mathrm{N}^{\wedge} \mathrm{C}\right)\right)$ contributions, see the ESI $\uparrow$. This visible absorption band is more redshifted and more intense in Pt-B than in Pt-A. According to theory, this is potentially related to the dominating $\mathrm{P}$ conformation in Pt-A contrasting with Pt-B. Indeed, calculations performed on the AP Pt-A predict a more intense absorption in the $400-500 \mathrm{~nm}$ domain than for the equivalent conformer of Pt-B.

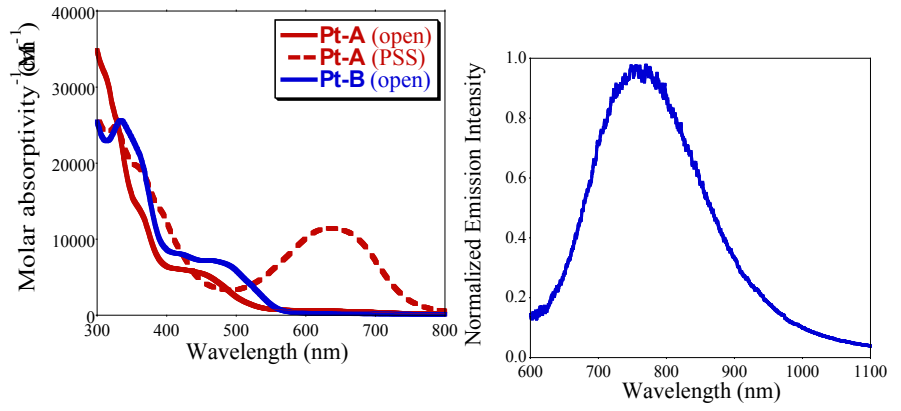

Figure 2 Left: Absorption spectra in $\mathrm{CH}_{2} \mathrm{Cl}_{2}$ at $298 \mathrm{~K}$ of Pt-A (open: full red line, PSS after irradiation at $350 \mathrm{~nm}$ : broken red line) and Pt-B (open: full blue line). Right: Emission spectrum of Pt-B in degassed $\mathrm{CH}_{2} \mathrm{Cl}_{2}$ solution $\left(\lambda_{\mathrm{ex}}=436 \mathrm{~nm}, \mathrm{C} \approx 10^{-5} \mathrm{M}\right)$.

Table 1. UV-visible absorption in $\mathrm{CH}_{2} \mathrm{Cl}_{2}$ at $298 \mathrm{~K}$ of Pt-A and Pt-B in their open and closed (PSS) forms together with the conversion percentage.

\begin{tabular}{cccc}
\hline & $\begin{array}{c}\lambda_{\mathrm{abs}} \mathrm{a} / \mathrm{nm}\left(\varepsilon 10^{3} / \mathrm{M}^{-1} \mathrm{~cm}^{-1}\right) \\
\text { Open }\end{array}$ & $\begin{array}{c}\lambda_{\mathrm{abs}} \mathrm{a} / \mathrm{nm} \\
(P S S)^{\mathrm{b}}\end{array}$ & $\begin{array}{c}\% \mathrm{C} \\
{ }_{\mathrm{c}}\end{array}$ \\
\hline Pt-A & $330(25.0) 365(13.4) 455(5.3)$ & 640 & $>90$ \\
Pt-B & $330(25.1) 365(20.5) 420(7.8) 490(6.4)$ & $/$ & \\
\hline
\end{tabular}

${ }^{\mathrm{a}}$ in $\approx 2.5 \times 10^{-5} \mathrm{M} \mathrm{CH}_{2} \mathrm{Cl}_{2}$ solution; ${ }^{\mathrm{b}}$ PSS : Closed form at the PSS after irradiation at $350 \mathrm{~nm} ;{ }^{\circ}$ Conversion estimated from ${ }^{1} \mathrm{H}$ NMR.

Remarkably, Pt-A can be efficiently converted into its closed form upon irradiation at 350 or $450 \mathrm{~nm}$ in $\mathrm{CH}_{2} \mathrm{Cl}_{2}$ (Scheme 1), while for Pt-B no photochromic reaction takes place in the same conditions. An almost quantitative conversion ( $>90 \%$ spectroscopic yield by ${ }^{1} \mathrm{H}$ NMR, see ESI $\dagger$ ) of the open Pt-A into the closed isomer is reached, and the hallmark visible absorption band of the closed DTE unit appears (Figure 2). ${ }^{8}$ In Pt-A, intramolecular stacking interactions are only possible in the $\mathrm{P}$ form, so that there is only a small amount of AP structure at any given time in solution, but it can easily be converted into the closed form that is only slightly higher in energy (6.3 kcal.mol ${ }^{-1}$, see below and ESI $\dagger$ ). The absence of ring-closing in Pt-B is more surprising given that the AP form presents an adequate molecular orbital topology for cyclisation. However, in Pt-B, there are stacking interactions in both AP and P, but not in the closed form that is much less stable $\left(>35 \mathrm{kcal}^{\mathrm{mol}}{ }^{-1}\right)$ and presents also an elongated central $\mathrm{CC}$ bond (see the ESI $\dagger$ ). The thermal stabilities of the closed DTE were theoretically investigated and the results are given in Figure 3. In Pt-A, there is a very high closed-to-open thermal isomerization barrier on the singlet potential energy surface, whereas in Pt-B, this barrier is much reduced. Given that triplet reaction pathways, resulting from intersystem crossing (ISC), have also been found in metal-DTE structures, ${ }^{9}$ we have explored the corresponding triplet energy surface. Interestingly, one notices a downhill path for Pt-A from the open to the closed form, indicating that ISC to the triplet state will lead to a barrierrless ring-closing. In contrast, in Pt-B, the thermal stability of the closed form is also very small in the triplet case, the open form remaining the most stable. This provides an explanation of the experimental outcomes: in Pt-A, one finds a standard behaviour for the thermal stability of the closed DTE and an efficient triplet ring-closing pathway, whereas in Pt-B, irrespective of the considered path, the closed form is unstable. 

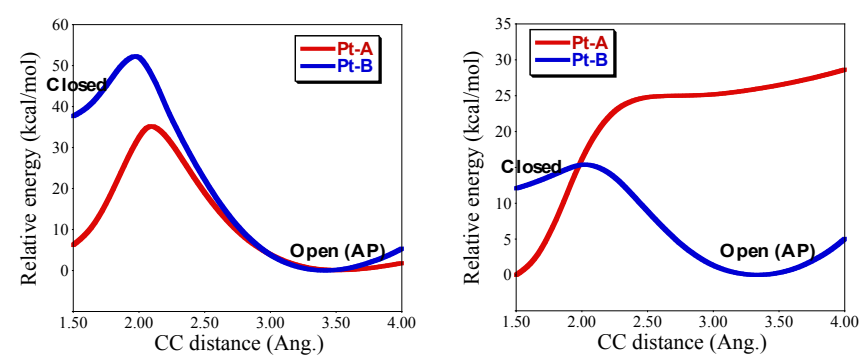

Figure 3 Smoothed DFT relaxed energy scan of the central DTE CC bond going from the closed to the AP form of Pt-A and Pt-B considering the singlet (left) and triplet (right) potential energy surfaces. The energetic zero is set for the most stable point for each system (see the ESI $\dagger$ for details).

Complex Pt-A is non emissive, most probably as the result of the competitive ring-closure process: ISC to the triplet state will induce cyclisation of the open DTE (see Figure 3, right). ${ }^{8}$ Interestingly, the emission spectrum $\left(\lambda_{\text {ex }}=436 \mathrm{~nm}, \mathrm{CH}_{2} \mathrm{Cl}_{2}\right.$, $298 \mathrm{~K}$ ) of the dinuclear complex Pt-B, displays a deep red emission band at $765 \mathrm{~nm}(\phi=0.0009$, Figure 2, right). This band cannot be assigned to a monomer-like emission since the wavelength is too low in energy, falling in the near-infrared region of the spectrum. ${ }^{7}$ Moreover, we found the emission is not concentration dependent ruling out an intermolecular aggregation. The good match between the absorption and excitation spectra suggests an excimeric emission originating from intramolecular interactions. As observed before, the AP conformation favours interfacial $\pi-\pi$ interactions of the cyclometalated $\mathrm{N}^{\wedge} \mathrm{N}^{\wedge} \mathrm{C}$ ligand and the terminal phenyl ring which can lead to excimeric ${ }^{3}\left(\pi-\pi^{*}\right)$ excited states responsible of the $765 \mathrm{~nm}$ emission of Pt-B. Note that the P conformer of Pt-B having a face-to-face conformation could also lead to a similar emissive behavior from Metal-Metal-to-Ligand Charge Transfer MMLCT ${ }^{3}\left(\mathrm{~d} \sigma^{*} \rightarrow \pi^{*}\right)$ and/or excimeric ${ }^{3}\left(\pi-\pi^{*}\right)$ excited states. We underline that, only a few examples of rigidly- or flexibly-linked platinum complexes have been reported, some giving rise to intra- and/or intermolecular excimers. In the case of flexibly-linked binuclear species, an equilibrium of different conformations with and without Pt...Pt and $\pi-\pi$ interactions is generally observed, ${ }^{10}$ whereas the use of the xanthene unit ${ }^{11}$ allows to lock the organometallic fragments in a face-to-face fashion. As a consequence, the bimetallic complex Pt-B displays a new type of molecular architecture offering a route to a deep-red triplet emitter.

Remarkably both Pt-B and Pt-A are characterised by large second-order NLO properties as determined by the electricfield induced second harmonic generation (EFISH) method ${ }^{6}$ which affords the product " $\mu \beta_{\text {EFISH" where }} \mu$ is the dipole moment and $\beta_{\mathrm{EFISH}}$ is the projection along the dipole moment axis of the vectorial component of the tensor of the quadratic hyperpolarisability. By working in DMF with an incident wavelength of $1.907 \mu \mathrm{m}, \mathbf{P t}-\mathbf{B}$ is characterized by a $\mu \beta_{\mathrm{EFISH}}$ value of $-590 \times 10^{-48} \mathrm{esu}$, slightly higher than that previously reported for mononuclear $\mathrm{Pt}(\mathrm{II})$ complexes linked through an open DTE unit. ${ }^{6} \mathbf{P t}-\mathbf{A}$ in its open form is also characterised by a good $\mu \beta_{\text {EFISH }}$ value $\left(-370 \times 10^{-48}\right.$ esu $)$ which increases by a factor of 4.5 upon irradiation at $350 \mathrm{~nm}$ in $\mathrm{CH}_{2} \mathrm{Cl}_{2}$ due to the formation of the closed form $\left(\mu \beta_{\mathrm{EFISH}}=-1670 \times 10^{-48} \mathrm{esu}\right)$. DFT calculations indicate that the dipole moment of the closed Pt-A (2.2 D) is about half the one of its AP open counterpart (4.2 D), indicating that the first hyperpolarizability values indeed strongly increases (by almost one order of magnitude) when the DTE closes.

In conclusion, we have synthesised and characterised two covalently linked dinuclear platinum complexes sharing a similar DTE bridge. Their completely different photochromic and luminescent properties were rationalised by theoretical calculations. Moreover, the excellent photochromic properties of Pt-A allow photoinduced switching of its second-order nonlinear optical response. This work illustrates the important role of the architecture of DTE-based complexes through intramolecular $\pi$-stacking interactions in the open form, giving rise to divergent properties. These interactions have a direct impact on the stability of the conformers, allowing either a switching behavior or an excimeric emission. This opens up new routes towards efficient organometallic photochromes versus deep-red emitters.

D.J. thanks Dr. Fihey for fruitful discussions. L. Toupet and T. Roisnel (CDIFX) are acknowledged for X-ray diffraction studies. D.J. acknowledges the ERC for financial support in the framework of Starting Grant (Marches - 278845). This research used resources of the GENCI- CINES/IDRIS and the CCIPL.

\section{Notes and references}

1 (a) V. Guerchais, L. Ordronneau and H. Le Bozec, Coord. Chem. Rev., 2010, 254, 2533; (b) C. C. Ko and V. W.-W. Yam, J. Mater. Chem., 2010, 20, 2063; (c) M. Irie, T. Fukaminato, K. Matsuda and S Kobatake, Chem. Rev., 2014, 114, 12174; (d) E. C. Harvey, B. L. Feringa, J. G. Vos, W. R. Browne and M. T. Pryce, Coord. Chem. Rev., 2015, 282-283, 77.

2 A. Fihey, A. Perrier, W. R. Browne and D. Jacquemin, Chem. Soc. Rev., 2015, 44, 3719

3 (a) A. Perrier, F. Maurel and D. Jacquemin, J. Phys. Chem. C, 2011, 115, 9193; (b) A. Fihey and D. Jacquemin, Chem. Sci., 2015, 6, 3495; (c) B. Lasorne, A. Fihey, D. Mendive-Tapia and D. Jacquemin, Chem. Sci., 2015, 6, 5695.

4 (a) V. Aubert, V. Guerchais, E. Ishow, K. Hoang-Thi, I. Ledoux, K. Nakatani and H. Le Bozec, Angew. Chem. Int. Ed., 2008, 47, 577; (b) L. Ordronneau, V. Aubert, R. Métivier, E. Ishow, J. Boixel, K. Nakatani, F. Ibersiene, D. Hammoutène, A. Boucekkine, H. Le Bozec and V. Guerchais, Phys. Chem. Chem. Phys., 2012, 14, 2599; (c) H. Nitadori, L. Ordronneau, J. Boixel, D. Jacquemin, A. Boucekkine, A. Singh, M. Akita, I. Ledoux, V. Guerchais and H. Le Bozec, Chem. Commun., 2012, 48, 10395; (d) L. Ordronneau, V. Aubert, V. Guerchais, A. Boucekkine, H. Le Bozec, A. Singh, I. Ledoux and D. Jacquemin, Chem. Eur. J., 2013, 19, 5845; (e) L. Ordronneau, H. Nitadori, I. Ledoux, A. Singh, J. A. G. Williams; M. Akita, V. Guerchais and H. Le Bozec, Inorg. Chem., 2012, 51, 5627.

5 (a) G. Guirado, C. Coudret and J.-P. Launay, J. Phys. Chem. B, 2007, 111, 2770; (b) K. A. Green, M. P. Cifuentes, T. C. Corkery, M. Samoc and M. G. Humphrey, Angew. Chem., Int. Ed., 2009, 48, 7867; (c) Y. Tanaka, T. Ishisaka, A. Inagaki, T. Koike, C. Lapinte, and M. Akita Chem. Eur. J. 2010, 16, 4762; (d) Y. Lin, J. Yuan, M. $\mathrm{Hu}, \mathrm{Z}$. Li, G.-A. Yu and S. H. Liu, Organomet., 2010, 29, 2808; (e) S. K. Brayshaw, S. Schiffers, A. J. Stevenson, S. J. Teat, M. R. 
Warren, R. D. Bennett, I. V. Sazanovich, A. R. Buckley, J. A. Weinstein and P. R. Raithby, Chem. Eur. J., 2011, 17, 4385; (f) F. Meng, Y. M. Hervault, L. Norel, K. Costuas, C. Van Dyck, V. Geskin, J. Cornil, H. H. Hng, S. Rigaut and X. Chen, Chem. Sci. 2012, 3, 3113; (g) Y. Lin, C. Jiang, F. Hu, J. Yin, G.-A. Yu and S. H. Liu, Dyes Pigm., 2013, 99, 995; (h) Y. Liu, C. M. Ndiaye, C. Lagrost, K. Costuas, S. Choua, P. Turek, L. Norel, and S. Rigaut, Inorg. Chem., 2014, 53, 8172; (i) F. Meng, Y. M. Hervault, Q. Shao, B. Hu, L. Norel, S. Rigaut, X. Chen, Nature Comm. 2014, 5, 3023.

6 (a) J. Boixel, V. Guerchais, H. Le Bozec, D. Jacquemin, A. Amar, A. Boucekkine, A. Colombo, C. Dragonetti, D. Marinotto, D. Roberto, S. Righetto and R. De Angelis, J. Am. Chem. Soc., 2014, 136, 5367; (b) J. Boixel, V. Guerchais, H. Le Bozec, A. Chantzis, D. Jacquemin, A. Colombo, C. Dragonetti, D. Marinotto and D. Roberto, Chem. Commun., 2015, 51, 7805.

7 W. Lu, B.-X. Mi, M. C. W. Chan, Z. Hui, C.-M. Che, N. Zhu, and S. T. Lee, J. Am. Chem. Soc., 2004, 126, 4958.

8 M. N. Roberts, J. K. Nagle, M. B. Majewski, J. G. Finden, N. R. Branda and M. O. Wolf, Inorg. Chem., 2011, 50, 4956.

9 (a) M. N. Roberts, C. J. Carling, J. K. Nagle, N. R. Branda and M. O. Wolf, J. Am. Chem. Soc., 2009, 131, 16644; (b) R. T. F. Jukes, V. Adamo, F. Hartl, P. Belser and L. de Cola, Inorg. Chem., 2004, 43, 2779.

10 (a) S. Develay and J. A. G. Williams, Dalton Trans., 2008, 4562; (b) Z. Guo and M. C. W. Chan, Chem. Eur. J. 2009, 15, 12585; (c) R. Munoz-Rodriguez, E. Bunuel, J. A. G. Williams and D. J. Cardenas, Chem. Commun., 2012, 48, 5980.

11 (a) V. W.-W. Yam, K. H.-Y. Chan, K. M.-C. Wong and B. W.-K. Chu, Angew. Chem. Int. Ed. 2006, 45, 6169; (b) K. H.-Y. Chan, H.S. Chow, K. M.-C. Wong, M. Ch.-L. Yeung and V. W.-W. Yam, Chem. Sci., 2010, 1, 477; (c) S. Y.-L. Leung, A. Y.-Y. Tam, C.-H. Tao, H. S. Chow and V. W.-W. Yam, J. Am. Chem. Soc. 2012, 134 1047; (d) X.-S. Xiao, W. Lu and C.-M. Che, Chem. Sci., 2014, 5, 2482; (e) A. Gross, T. Moriuchi and T. Hirao, Chem. Commun., 2013, 49, 1163. 


\section{TOC}

Two covalently linked dinuclear platinum complexes, Pt-A and Pt-B, sharing a similar DTE bridge, have been synthesised and characterised. Their completely different photochromic and luminescent properties were rationalised by theoretical calculations

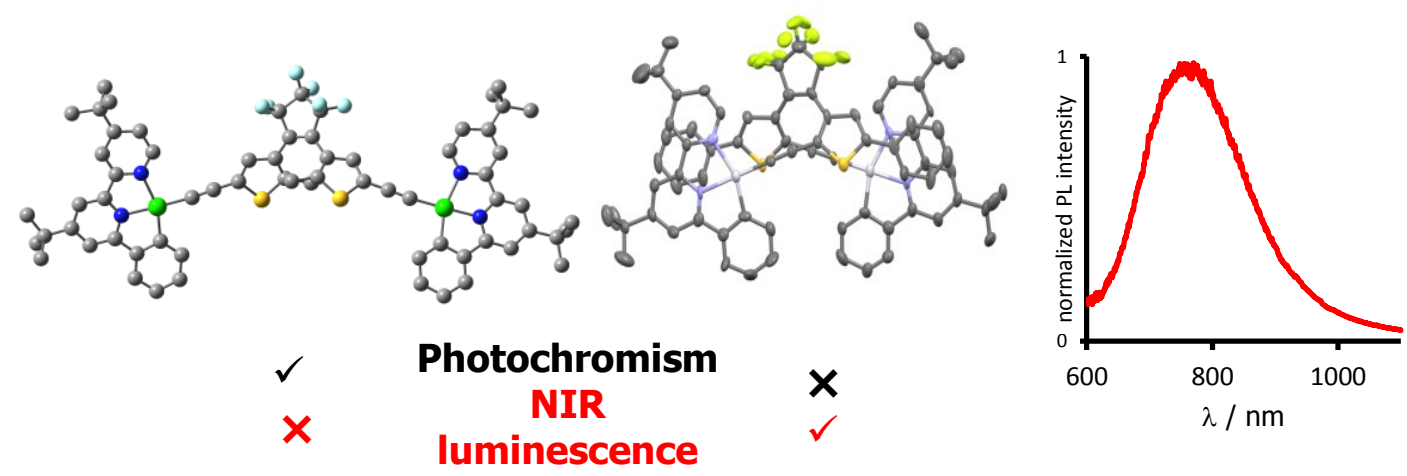

